\title{
Convergent Effects of Acute Stress and Glucocorticoid Exposure upon MA0-A in Humans
}

\author{
Alexandra Soliman, ${ }^{1}$ Chinelo Udemgba, ${ }^{2}$ Ian Fan, ${ }^{1} \mathrm{Xin} \mathrm{Xu},{ }^{1}$ Laura Miler, ${ }^{1}$ Pablo Rusjan, ${ }^{1}$ Sylvain Houle, ${ }^{1}$ \\ Alan A. Wilson, ${ }^{1}$ Jens Pruessner, ${ }^{3,4}$ Xiao-Ming $\mathrm{Ou},{ }^{2}$ and Jeffrey H. Meyer ${ }^{1}$ \\ ${ }^{1}$ CAMH Research Imaging Centre and Campbell Family Mental Health Research Institute, Centre for Addiction and Mental Health and Department of \\ Psychiatry, University of Toronto, Toronto, Ontario M5T 1R8, Canada, ${ }^{2}$ Department of Psychiatry and Human Behavior, University of Mississippi Medical \\ Center, Jackson, Mississippi 39216, ${ }^{3}$ Department of Psychiatry, McGill University, Montreal, Quebec H3A 1A1, Canada, and ${ }^{4}$ Douglas Hospital Research \\ Centre and McConnell Brain Imaging Centre, Montreal Neurological Institute, Montreal, Quebec H3A 2B4, Canada
}

Monoamine oxidase-A (MAO-A), a key brain enzyme which metabolizes monoamines, is implicated in the pathophysiology of stressrelated illnesses, including major depressive disorder, addiction, and violent behavior. Chronic stressors and glucocorticoidadministration typically associate with elevated MAO-A levels/activity. However, the relationship of shorter stress or glucocorticoid exposures and MAO-A levels/activity is not well established. Our objectives are to assess effects of acute stress upon MAO-A $V_{\mathrm{T}}$, an index of MAO-A density, in human brain and acute glucocorticoid exposure upon MAO-A levels in human neuronal and glial cell lines. Twelve healthy, non-smoking participants aged $18-50$ underwent $\left[{ }^{11} \mathrm{C}\right]$ harmine positron emission tomography to measure brain MAO-A $V_{\mathrm{T}}$ on two different days: One under acute psychosocial stress (via Trier Social Stress and Montreal Imaging Stress Tasks) and one under a non-stress condition. MAO-A density (by Western blot) and activity (by $\left[{ }^{14} \mathrm{C}\right]-5$-HT metabolism and liquid scintillation spectroscopy) were measured in human neuronal and glial cell lines after $4 \mathrm{~h}$ exposure to dexamethasone. We observed a significant reduction in whole-brain MAO-A binding as reflected by reductions in 10 of 11 brain regions. Acute dexamethasone exposure in neuronal and glial cells significantly decreased MAO-A activity and protein levels. We observed a highly consistent relationship between acute stressors and glucocorticoid administration and decreased MAO-A binding, activity and protein levels. Since MAO-A metabolizes monoamines, this phenomenon may explain why acute stressors benefit healthy animals even though chronic stress is associated with illness.

\section{Introduction}

Monoamine oxidase A (MAO-A) is an enzyme with several key roles including metabolizing monoamines, promoting oxidation, and contributing to apoptosis (Manoli et al., 2005; Ou et al., 2006a). Abnormally high or low MAO-A occur in the pathophysiology of high-impact conditions such as major depressive disorder, addiction, and violent behavior (Fowler et al., 1996; Meyer et al., 2006, 2009; Alia-Klein et al., 2008; Johnson et al., 2011; Soli-

Received May 1, 2012; revised Aug. 21, 2012; accepted Sept. 28, 2012.

Author contributions: A.S., J.P., X.-M.O., and J.H.M. designed research; A.S., C.U., I.F., X.X., L.M., and J.H.M. performed research; P.R., S.H., A.A.W., J.P., and J.H.M. contributed unpublished reagents/analytic tools; A.S., C.U., I.F., P.R., J.P., X.-M.O., and J.H.M. analyzed data; A.S., C.U., J.P., X.-M.O., and J.H.M. wrote the paper.

This work was supported by the Canadian Institutes of Health Research, the Ontario Mental Health Foundation, the Canadian Foundation for Innovation, the Ontario Innovation Trust, the Centre for Addiction and Mental Health Fellowship Award 2009, and the National Alliance for Research in Schizophrenia and Depression Young Investigator Award 2009-2010. We thank Dr. Ingrid Bacher, Dr. Isabelle Boileau, Dr. Julia Sacher, Jinoos Sotodeh, technicians Jeannie Fong, Laura Ng, Alvina Ng, and Shakevia Johnson, chemistry staff Armando Garcia, Jun Parks, Winston Stableford, and Min Wong, and engineers Terry Bell and Ted Harris-Brandts for their technical assistance.

Drs. Meyer, Wilson, and Houle have received operating grant funding for other studies from Eli Lilly, Lundbeck, and SK Life Science in the past 12 months, and Dr. Meyer has consulted to several of these companies. None of these companies participated in the design or execution of this study or writing the manuscript. Dr. Meyer is developing natural health products to treat high MAO-A states. Dr. Meyer is applying for patents to implement measures of utilizing MAO to diagnose or treat mood disorders. It is likely that companies which make medications affecting monoamine receptor or monoamine oxidase binding will seek collaborations with these investigators in the future.

Correspondence should be addressed to Dr. Jeffrey H. Meyer, College Street Site, Centre for Addiction and Mental Health, PET Centre, 250 College Street, Toronto, 0N M5T 1R8, Canada. E-mail: jeff.meyer@camhpet.ca.

DOI:10.1523/JNEUROSCI.2091-12.2012

Copyright $\odot 2012$ the authors $\quad 0270-6474 / 12 / 3217120-08 \$ 15.00 / 0$ man et al., 2011); which are also often exacerbated by acute stress (Kessler, 1997; Kim-Cohen et al., 2006; Dagher et al., 2009). However, most investigations have focused on the relationship of chronic stress and MAO-A level or activity.

Stress and glucocorticoid exposures lasting $24 \mathrm{~h}$ or longer have been associated with greater MAO-A synthesis, levels, and activity. Five day administration of dexamethasone or hydrocortisone caused 6- to 14-fold increases in MAO-A activity in human skin fibroblasts (Edelstein and Breakefield, 1986). Seven day dexamethasone administration to human myocytes revealed MAOA-mRNA upregulation and a sevenfold elevation of MAO-A protein levels (Manoli et al., 2005). Twenty four-hour, but not $12 \mathrm{~h}$ dexamethasone, treatment of human brain cells (neuronal and glial cell lines) was associated with greater MAO-A gene expression (Ou et al., 2006b). Dexamethasone administration over $26 \mathrm{~d}$ caused $300 \%$ increase in frontal/parietal cortex MAO-A activity in adult male Sprague Dawley rats (Slotkin et al., 1998), and chronic social stress from the social-defeat paradigm led to 2-3 times increased MAO-A-mRNA levels in the raphe nucleus of CBA/Lac mice (Filipenko et al., 2002). Hence, across cell lines and brain tissue, $24 \mathrm{~h}$ or longer exposures to stress or glucocorticoids are associated with greater MAO-A-mRNA, protein, or activity.

In contrast, MAO-A levels or activity in relation to shortened exposures to stress and glucocorticoids is not well established. One research group reported decreased $\mathrm{MAO}-\mathrm{A}$ whole-brain activity in rodents after one course of inescapable footshock (Lem- 

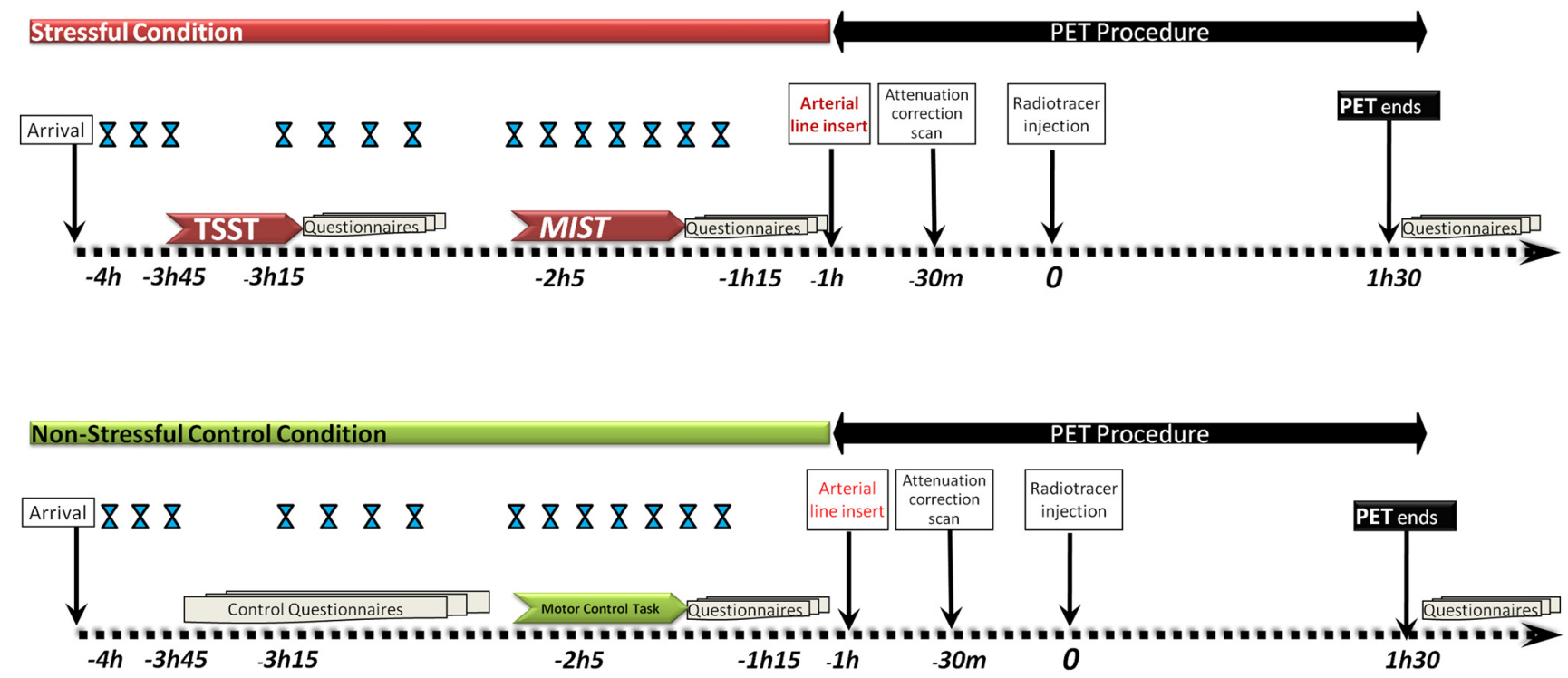

Time relative to functional PET scan (hours, minutes)

$\mathrm{Z}$ represents each cortisol saliva sample

Figure 1. Experimental design, PET study, acute stress and non-stressful control scan days. Acute stress involves difficult public speaking (TSST), followed by mental arithmetic tasks (MIST) under strict time pressure. Confederate audience gives scripted negative feedback. Non-stressful control involves questionnaires and a simple mental arithmetic control task with no time pressure. No confederate feedback given. Order of conditions was counterbalanced among subjects (acute stress vs non-stressful control).

oine et al., 1990; Armando et al., 1993). The data tentatively suggest a reduction in activity (which is correlated strongly with MAO-A enzyme levels in brain). However, to the best of our knowledge, no studies in humans have been performed investigating the effects of acute stress and glucocorticoid exposure on MAO-A levels.

To investigate the effects of acute stress upon MAO-A levels, we measured MAO-A density and activity after acute stress exposure. Our first objective was to assess the effects of acute stress upon MAO-A $V_{\mathrm{T}}$ in human brain using $\left[{ }^{11} \mathrm{C}\right]$ harmine positron emission tomography. MAO-A $V_{\mathrm{T}}$ is an in vivo index of MAO-A density and affinity, elevated during major depressive episodes (a chronically high-stress state; Meyer et al., 2006, 2009; Johnson et al., 2011). Next, we sought to determine whether the stressor's effects are mediated by increases in glucocorticoids. Our second objective was to assess the effect of acute $(4 \mathrm{~h})$ glucocorticoid exposure upon MAO-A density and activity in human neuronal and glial cell lines. We hypothesized that acute psychosocial stress would be associated with reduced brain MAO-A binding in vivo; and acute glucocorticoid administration with lower MAO-A levels and activity in cell lines.

\section{Materials and Methods}

There were two main sets of experiments. Experiment one studied the acute effects of stress upon MAO-A $V_{\mathrm{T}}$ in living humans using $\left[{ }^{11} \mathrm{C}\right]$ harmine positron emission tomography (PET); experiment two studied the effects of acute glucocorticoid administration on MAO-A protein density and activity in human neuroblastoma and glioblastoma brain-derived cell lines, respectively.

Experiment One-PET imaging in vivo and psychosocial stressors Subjects. Twelve healthy, non-smoking volunteers aged 19-46, with no history of neurotoxin, psychotropic, or antipsychotic use (mean age $31.1 \pm 8.0$; 6 males, 6 females) participated in the imaging study. Periand postmenopausal women were excluded: women $>42$ years and those reporting symptoms of perimenopause at a younger age were also excluded. The Structured Clinical Interview for DSM-IV (First et al., 1995) screened subjects for the exclusionary criteria which included current or past Axis I disorders, neurological conditions, current use of prescription medication including oral contraceptives, pregnancy, claustrophobia, metal in the body, use of over-the-counter medications within the last month, and herbal remedies within 3 months before scanning. Family history was determined by a structured set of questions that focused upon first degree relatives. On each $\left[{ }^{11} \mathrm{C}\right]$ harmine PET scan day, participants underwent common blood tests to rule out medical causes of disturbed mood (thyroid function, electrolyte levels, and complete blood cell count), and a urine drug screen which included over-the counter, psychotropic, and illicit drugs. After subjects were given complete description of procedures, written informed consent was obtained. The recruitment and experiments were approved by Research Ethics Board for Human Subjects at the Centre for Addiction and Mental Health, University of Toronto.

Overview of scan day protocol. Each subject underwent two $\left[{ }^{11} \mathrm{C}\right]$ harmine PET scans, one immediately following completion of the stress protocol and one immediately following the control task, on different days separated by $4-8$ weeks. Women were scanned in all phases of the menstrual cycle, and their phase was recorded by self report. In a previously collected sample, we observed no relationship between phase of menstrual cycle and MAO-A $V_{\mathrm{T}}$ (Meyer et al., 2009). Every PET scan began at the same time of day (between 2:30 and 3:30 P.M.), and Stress/ Control tasks and questionnaires commenced $\sim 3.5 \mathrm{~h}$ before. Scan order was counterbalanced across subjects. For the stress scanning session, subjects performed both the Trier Social Stress Test (TSST) and the Montreal Imaging Stress Task (MIST; see below), and completed associated questionnaires, continuously from $\sim 3.5 \mathrm{~h}$ before, until $\sim 60 \mathrm{~min}$ before the $\left[{ }^{11} \mathrm{C}\right]$ harmine scan (Fig. 1). The control session was identical in questionnaires and time spent before the scan, except that there was a motor control computer task in place of the MIST, comprising simple arithmetic questions with no time limit or peer evaluation. The afternoon hours are chosen because the circadian changes in cortisol are less pronounced in the afternoon, thereby enhancing our ability to detect an effect of our experimental manipulation upon cortisol levels.

Stress protocol. Psychological stress was induced by sequentially applying two procedures which have been found to be reliable, repeatable, and ethically sound: the TSST (Kirschbaum et al., 1993) and the MIST (De- 
dovic et al., 2005). The TSST consists of a period of stress-expectancy followed by subjects' performing a public speech, and subsequent verbal mental arithmetic; it consistently elicits a stress response in healthy humans (Kirschbaum et al., 1995). The MIST involves mental arithmetic challenges that must be answered under time pressure (see Dedovic et al., 2005 , for full description). Both tasks are standardized psychosocial stress tasks, which use elements of uncontrollability and additional social evaluative threat via disapproving verbal feedback given after each testing-block, and both tasks have been shown to induce behavioral and physiological stress and anxiety responses (Pruessner et al., 1999; Dedovic et al., 2005). During the non-stress control PET session, subjects performed a control arithmetic/motor task at the same time of day, but without time constraints, visible accuracy feedback or negative verbal feedback from a confederate experimenter, and completed identical questionnaires throughout the day.

Subjects completed the Spielberger State-Trait Anxiety Inventory (STAI) (Spielberger, 1977). The STAI measures state- and traitdependent anxiety; perception of stress was assessed four times during each PET scan day (arrival, after each stress task, and after the PET scan, before debriefing) by asking subjects to complete the STAI (Spielberger, 1977) as well as two visual analog scales (Pruessner et al., 2004) to assess feelings of negativity and uncontrollability, as well as affect, four times during each scan day. Saliva samples were collected every $12 \mathrm{~min}$ throughout the experiment. Saliva-derived cortisol was analyzed using a time-resolved fluorescence immunoassay (Dressendörfer et al., 1992), and quantification of cortisol data was done using area under the curve (total area under the curve, AUCg, representing total cortisol, and area under the curve with respect to cortisol increase, AUCi; cortisol in nanomoles per liter by time in minutes) calculations for each subject and each scanning session (Pruessner et al., 2003). The latter value equals AUCg minus the area under a straight line created by extending a straight line from the initial cortisol rise through to the completion of the cortisol rise. AUCi may be viewed as the differential effect of the stress protocol.

PET image acquisition and analysis. PET scans were obtained with a high resolution research tomograph (HRRT) PET camera (in-plane resolution; full width at half maximum, $3.1 \mathrm{~mm} ; 207$ axial sections of 1.2 $\mathrm{mm}$, Siemens Molecular Imaging). A dose of $\sim 370 \mathrm{MBq}$ of intravenous $\left[{ }^{11} \mathrm{C}\right]$ harmine was administered as a bolus for the PET scan and emission data were then acquired over a $90 \mathrm{~min}$ period. $\left[{ }^{11} \mathrm{C}\right]$ Harmine was of high radiochemical purity (mean $\pm \mathrm{SD} ; 98.9 \pm 0.8 \% ; n=24)$ and high specific activity (mean $\pm \mathrm{SD}, \mathrm{TBq} \cdot \mathrm{mmol}^{-1}, 85.8 \pm 33$ ) at time of injection. Measurement of radioactivity in whole blood and plasma was done as described previously (Meyer et al., 2009), and procedures used for frame acquisition and reconstruction have also been described previously (Meyer et al., 2006, 2009).

To complete region of interest (ROI) analysis, we acquired a T1weighted magnetic resonance imaging (MRI) scan on each subject for anatomical localization (GE Signa 1.5-T scanner; fast spoiled gradient echo, $\mathrm{T}_{1}$-weighted image; $x, y, z$ voxel dimensions, $0.78,0.78$, and 1.5 $\mathrm{mm}$, GE Healthcare). PET emission frames were summed and the individual's MRI was coregistered to each summed PET image using a mutual information algorithm (Studholme et al., 1999). ROIs were determined using a semiautomated method whereby regions on a template MRI are transformed onto the individual MRI via a series of transformations and deformations that match the template image to the coregistered MRI (Ashburner and Friston, 1997, 1999), followed by selection of gray matter voxels within the ROI (Ashburner and Friston, 1997; Rusjan et al., 2006). Each ROI was overlaid upon both the coregistered MRI and summated $\left[{ }^{11} \mathrm{C}\right]$ harmine PET image for visual anatomical confirmation.

The ROIs were selected for their functional or neurochemical relevance in humans to stress-responses, emotional regulation, and/or impulsivity (Drevets, 2000; Pruessner et al., 2004; Frokjaer et al., 2008; Soliman et al., 2008; Love et al., 2009). The ROIs sampled were the whole prefrontal cortex (and subregional ROI of orbitofrontal and dorsolateral prefrontal cortex), anterior cingulate cortex (including Brodmann areas 24 , part of 32), putamen, caudate, thalamus, anterior temporal cortex (Brodmann areas 38, part of 20,21,22), occipital cortex, midbrain, and hippocampus. Total volume of distribution $\left(V_{\mathrm{T}}\right)$ is an index of harmine binding and represents the concentration of the total radiotracer in tissue relative to plasma concentration at equilibrium (Ginovart et al., 2006). MAO-A $V_{\mathrm{T}}$ was calculated using the Logan method with a plasma arterial input (Logan et al., 1990). When using $\left[{ }^{11} \mathrm{C}\right]$ harmine PET, the Logan method for $\mathrm{MAO}-\mathrm{A} V_{\mathrm{T}}$ is comparably robust in magnitude alongside the kinetically determined two-tissue compartment model, and computationally efficient (Ginovart et al., 2006).

Statistical analyses of neuroimaging data. The primary analyses used repeated-measures multivariate ANOVA (MANOVA) to determine whether there is a whole-brain effect of condition (stress/control) on MAO-A $V_{\mathrm{T}}$, the dependent measure. We hypothesized that the effect would be widespread as the evidence to support a region-specific effect on MAO-A in particular is limited. The regional ANOVAs were explored only if there was a significant omnibus effect in the MANOVA. We also conducted paired $t$ tests on the total cortisol output in the stress condition compared with the control (using AUC calculations as described above) to examine whether the stress condition elicited more salivary cortisol secretion over the test time-period than the control condition. It was planned not to include age or gender in the primary analyses as it was expected that these would have no effect upon MAO-A binding based on the absence of a relationship between either of these factors and MAO-A level or MAO-A $V_{\mathrm{T}}$ (Saura et al., 1997; Meyer et al., 2006, 2009).

\section{Experiment Two-Cell lines and acute glucocorticoid treatment} Cell lines, cell culture, and treatment. Human neuroblastoma cell line, SH-SY5Y, was purchased from the American Type Culture Collection. 1242-MG, human glioblastoma cell line, was acquired from Dr. B. Westermark (Department of Pathology, University Hospital, Uppsala, Sweden; Tazik et al., 2009). Both cell lines were cultured in DMEM (Invitrogen) supplemented with glutamine and 10\% fetal bovine serum.

SH-SY5Y and 1242-MG cells were seeded into $10 \mathrm{~cm}$ dishes for each cell line and cultured in supplemented DMEM at $37^{\circ} \mathrm{C}$ in $5 \% \mathrm{CO}_{2}$ and $95 \%$ humidity until cells were $80 \%$ confluent. The cells in each dish were then treated with or without dexamethasone (100 nM) for $4 \mathrm{~h}$ representing acute stress.

MAO-A catalytic activity assay. Dexamethasone-treated SH-SY5Y and 1242-MG cells were washed and harvested using PBS and centrifuged for $10 \mathrm{~min}$ at $4^{\circ} \mathrm{C}(8000 \times \mathrm{g})$; the cell pellets were resuspended in $140 \mu \mathrm{l}$ of assay buffer (50 mM sodium phosphate buffer, $\mathrm{pH} 7.4$ ), homogenized, and sonicated. One hundred microliters of the total protein were incubated with $100 \mu \mathrm{M}\left[{ }^{14} \mathrm{C}\right]-5-\mathrm{HT}$ in the assay buffer for $20 \mathrm{~min}$ at $37^{\circ} \mathrm{C}$. The reaction was terminated by adding $100 \mu \mathrm{l}$ of $6 \mathrm{~N} \mathrm{HCl}$. Benzene/ethyl acetate (1:1) was incorporated and the reaction product was extracted after centrifugation at room temperature for $7 \mathrm{~min}$. Radioactivity was measured by liquid scintillation spectroscopy. The values were normalized using total protein concentration (Ou et al., 2006b; Johnson et al., 2011).

Western blot analysis. Following dexamethasone treatment, SH-SY5Y and 1242-MG cells were washed in PBS and harvested in radioimmunoprecipitation assay buffer (RIPA buffer, Sigma) plus protease inhibitor (1:1). After centrifugation for $10 \mathrm{~min}$ at $4^{\circ} \mathrm{C}(8000 \times g)$, the supernatant was collected and sonicated. Sixty micrograms of total protein was separated by $10 \%$ SDS-PAGE and transferred to polyvinylidene fluoride membrane. The membrane was then blocked with $5 \%$ nonfat dry milk in Tris-buffered saline (10 nм Tris- $\mathrm{HCl}, \mathrm{pH} 7.5,150 \mathrm{~mm} \mathrm{NaCl}$ ) at room temperature for $45 \mathrm{~min}$. Afterward, the membrane was incubated with mouse anti-MAO-A antibody (1:125; Santa Cruz Biotechnology) overnight at $4^{\circ} \mathrm{C}$ and, subsequently, incubated with the secondary antibody (1:1000; Santa Cruz Biotechnology) for $2 \mathrm{~h}$. The bands were visualized using ChemiDoc XRS + Imaging System (Bio-Rad; Lu et al., 2008; Johnson et al., 2011).

$\beta$-Actin levels, used as a loading control, were determined by stripping the same immunoblotted membrane and incubating the membrane overnight at $4^{\circ} \mathrm{C}$ in mouse anti- $\beta$-actin antibody (1:10,000; Millipore) followed by incubation in secondary antibody (1:2000; Santa Cruz Biotechnology) for $2 \mathrm{~h}$. The band intensities for MAO-A and $\beta$-actin were obtained by Quantity One analysis software. $\beta$-Actin levels were used to normalize the final band intensities for MAO-A protein levels. 


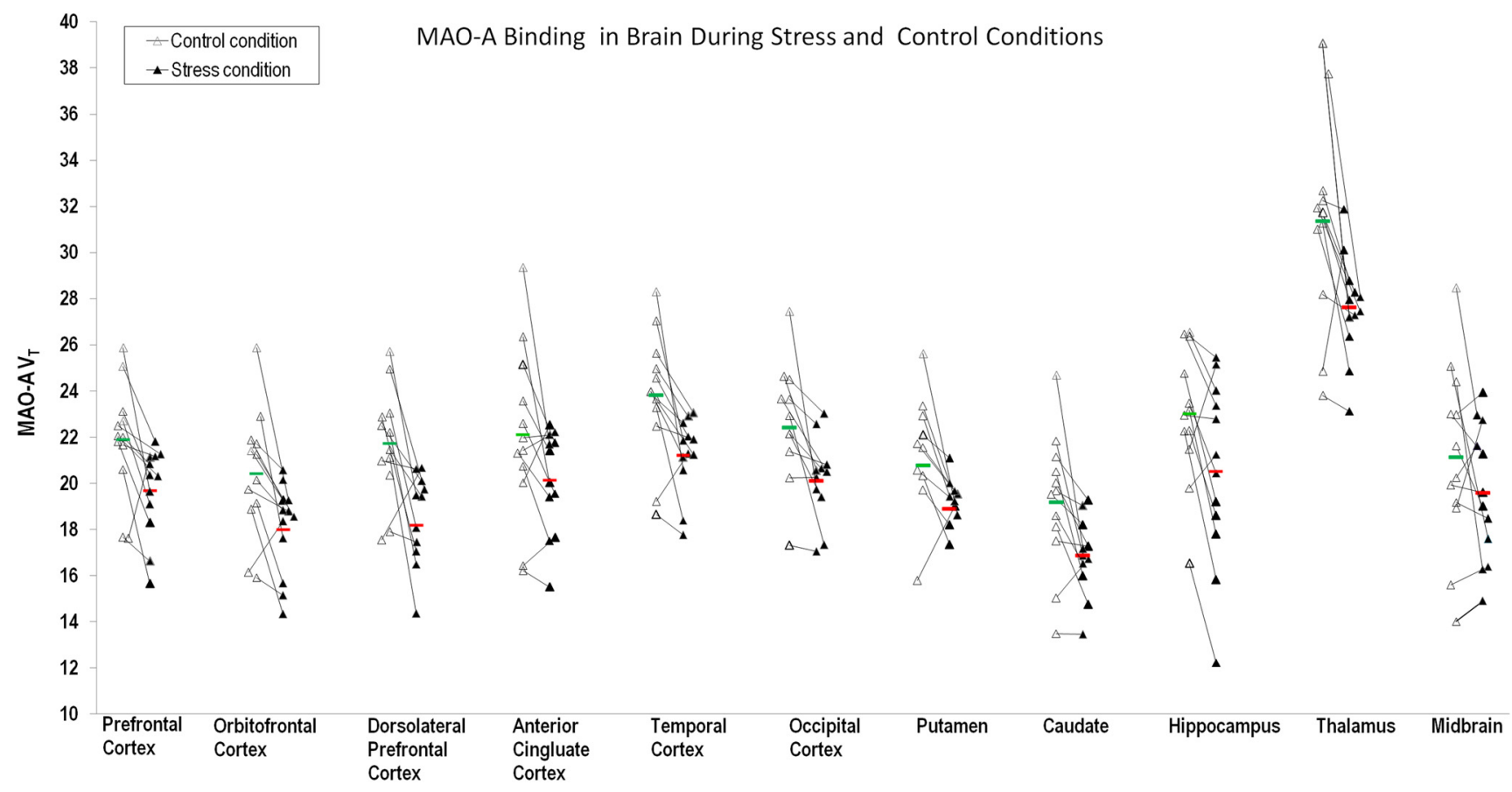

Figure 2. MANOVA showed a main effect of condition on whole-brain MAO-A binding $\left(F_{(1,11)}=2505, p=0.016\right)$. Pairwise univariate ANOVAs within the MANOVA showed the stress-induced effect to be significant in all regions except for the midbrain.

Table 1. Stress-induced differences in brain MAO-A binding

\begin{tabular}{lrlcr}
\hline Measure & \multicolumn{3}{c}{ Mean \% difference } \\
\hline Prefrontal cortex & 9.5 & 0.010 & -9.4 & SD \\
Orbitofrontal cortex & 13.0 & 0.004 & -11.1 & 11.7 \\
dIPFC & 15.8 & 0.002 & -15.4 & 11.0 \\
ACC & 5.2 & 0.043 & -7.6 & 14.5 \\
Temporal cortex & 12.6 & 0.005 & -10.0 & 12.0 \\
Occipital cortex & 10.3 & 0.008 & -9.4 & 9.8 \\
Putamen & 7.2 & 0.021 & -7.9 & 9.7 \\
Caudate & 10.0 & 0.009 & -10.7 & 11.4 \\
Hippocampus & 8.2 & 0.015 & -10.9 & 11.7 \\
Thalamus & 8.5 & 0.014 & -10.5 & 14.0 \\
Midbrain & 2.1 & 0.176 & -5.4 & 13.3 \\
\hline
\end{tabular}

Repeated-measures MANOVA examining whole brain (11 regions) showed MAO-A binding was reduced in whole brain during the stressful condition, compared with the control condition (Multivariate $F_{(111)}=2505, p=0.016$ ); individual regions uncorrected for multiple comparisons (MANOVA was significant). ACC, Anterior cingulate cortex; dIPFC, dorsolateral prefrontal cortex.

Statistical analysis for cell line measurements of MAO-A activity and density. The statistical significance was evaluated using Student's $t$ test for differences between two groups in each cell line. A value of $p<0.05$ was considered to be significant.

\section{Results}

\section{Effects of acute stress on MAO-A $V_{\mathrm{T}}$}

We hypothesized stress would affect multiple brain regions, and these were included in a repeated-measures MANOVA. The repeated-measures MANOVA resulted in a significant omnibus effect: a decrease in whole-brain MAO-A $V_{\mathrm{T}}$ in the stress condition compared with the control condition, indicative of a decrease in available MAO-A for binding by $\left[{ }^{11} \mathrm{C}\right]$ harmine $\left(F_{(1,11)}\right.$ $=2505, p=0.016$, Figure 2). We observed a $7.9-15.7 \%$ binding reduction in the significant regions in the stress condition compared with the control scan (Table 1). In Figure 2, there was one subject who had a change in MAO-A in the opposite direction and this subject differed from the others in that this subject had experienced a recent bereavement (within the previous 12 months). Subsequent pairwise univariate ANOVAs of prefrontal cortical regions MANOVA showed the stress-induced effect to be significant in all 3 prefrontal cortex regions: prefrontal $\left(F_{(1,11)}=\right.$ 9.5, $p=0.010)$, orbitofrontal $\left(F_{(1,11)}=13.0, p=0.004\right.$ dorsolateral prefrontal $\left(F_{(1,11)}=15.8, p=0.002\right.$; and every other region but the midbrain.

\section{Psychological and neuroendocrine effects of acute stress \\ Greater increases in cortisol on stress day}

The stress session resulted in significantly greater increases in salivary cortisol (nmol/L) compared with control session. All calculations used area under the curve increase during stress (AUCi units, $\mathrm{nmol} / \mathrm{L} \times$ min; mean AUCi difference $328 \pm 274 ; t_{(10)}=$ 3.97; $p=0.003$, Fig. 3, top and middle).

\section{Self-report stress increased after stress tasks}

Subjects reported significantly increased state-anxiety, as measured by STAI, after the stress tasks $(38.0 \pm 11.3)$ compared with state-anxiety reported upon arrival $(28.2 \pm 5.6)$, on the stress day (mean difference 9.75, $\pm 10.6, t_{(11)}=3.20, p=0.008$ ). At the time of arrival anxiety was similar on the stress day and control day $\left(t_{(11)}=0.29, p=0.777\right.$, n.s. $)$. However, state-anxiety scores were greater at subsequent time-points on the stress day compared with the control day state-anxiety scores (after stress tasks $t_{(11)}=$ $3.60, p=0.004$; after scan $t_{(10)}=2.33, p=0.04$ (one subject did not complete the post-scan stress measure; Fig. 3 , bottom).

\section{Self-report stress did not change after control tasks}

To rule out coincidental elevated anxiety on the stress day, paired-sample $t$ tests were used to measure state-anxiety increases between arrival and post-stress tasks. Finally, there was no change in state-anxiety scores between arrival and after control tasks on the same day (mean difference $=2.00 \pm 6.4, t_{(11)}=1.08, p=$ 0.305 , n.s.). 

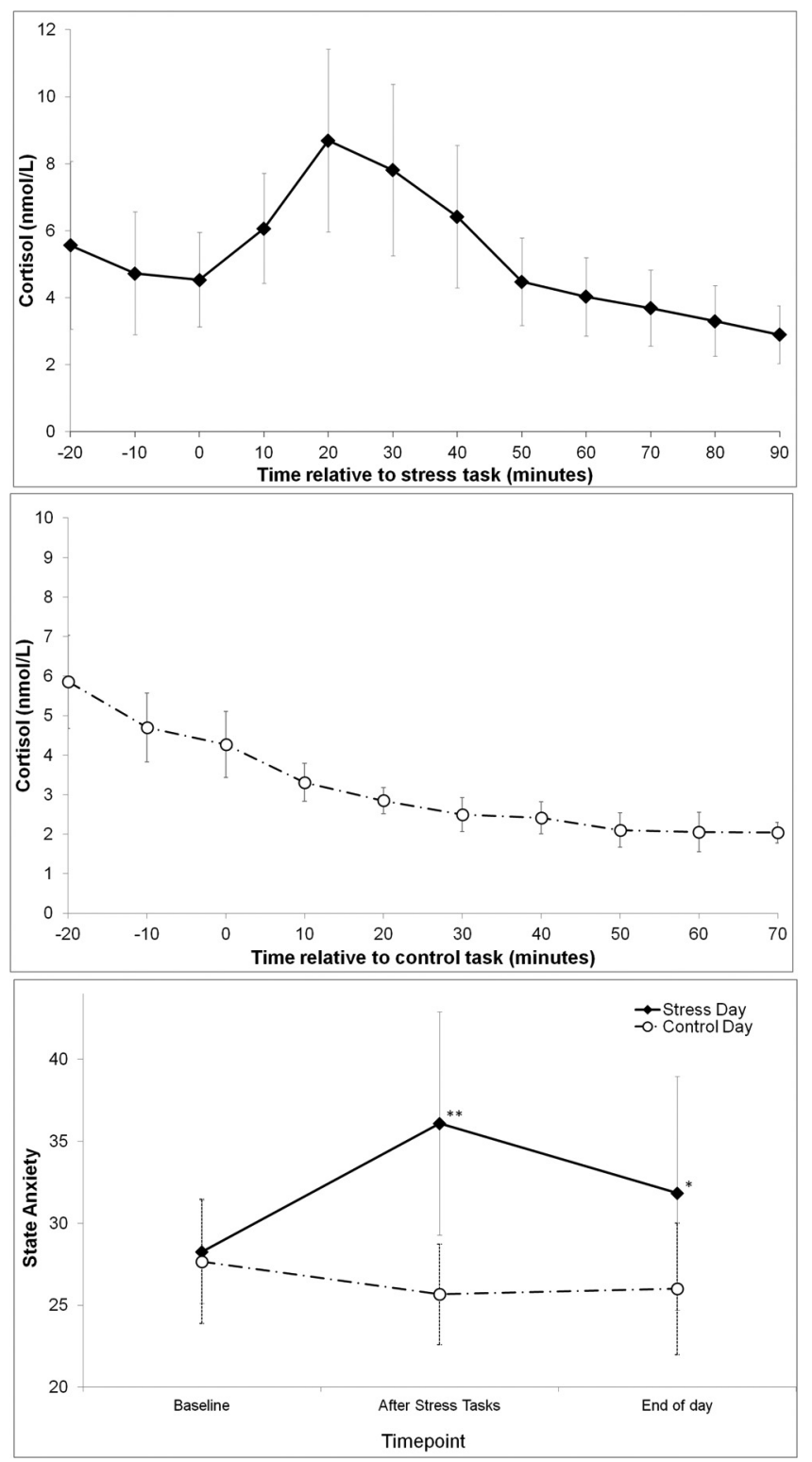

Figure 3. Greater cortisol output and subjective reports of stress during acute psychosocial stressors (TSST, MIST) and control motor task in healthy control subjects. The total cortisol output was greater on the stress vs control test day, and shows the expected stress-induced peak in cortisol. The control day shows the expected diurnal decline in cortisol. On both days, saliva samples were collected every 10-15 min throughout the experimental and control procedures. Saliva-derived cortisol was analyzed using a time-resolved fluorescence immunoassay (Dressendörfer et al., 1992) and quantification of cortisol data was done using under the curve (AUC; $\mu \mathrm{g} / \mathrm{dl} / \mathrm{min}$ ) calculations for each subject and each scanning session (Pruessner et al., 2003). The within-subject error bars are $95 \%$ confidence intervals based upon the SEM. Top, Stress day. All subjects performed a series of two psychosocial stress tasks (TSST, MIST) during the $4 \mathrm{~h}$ before PET scanning, and 12 salivary cortisol samples were collected. Sample 0 represents the mean of the sample immediately before the first stress-related cortisol increase is observed, which corresponds to the sample taken immediately before performing the TSST. Middle, Control day. Subjects completed a control (motor-visual) task. Sample 0 represents the mean of the control-day sample which corresponds to the time of sample 0 from the stress day (i.e., the sample taken immediately before the stress-related increase in cortisol). Bottom, Self-report stress measures. The STAl was used to measure self-reported momentary anxiety throughout each scanning day, with possible scores ranging from 20 to 80 . Subjects completed the STAl three times each scanning day: upon arrival, immediately after all stress-inducing protocols, and immediately after exiting the PET scanner. For each time point except upon arrival, Trait Anxiety was significantly higher on the stress day compared with the control day, as measured by paired samples $t$ test. Difference in State Anxiety: ${ }^{* *} p \leq 0.01,{ }^{*} p \leq 0.05$ significance.
No differences in baseline stress reports between scan days

There was no effect of day (control vs stress days) on baseline state-anxiety scores (mean difference $0.58, \pm 7.0, t_{(11)}=0.29, p=$ 0.777 , n.s.).

\section{Effects of acute dexamethasone exposure upon MAO-A enzyme activity in human neuronal and glial cells}

To examine the effects of acute stress on MAO-A in vitro, the enzymatic activity of MAO-A was investigated in human brain cell lines, SH-SY5Y (neuroblastoma) and 1242-MG (glial). Before the determination of MAO-A catalytic activity, cells were treated with $100 \mathrm{~nm}$ dexamethasone for $4 \mathrm{~h}$ as this concentration of dexamethasone (100 nM) has been reported to increase MAO-A activity in a chronic treatment model $(>12 \mathrm{~h})$. Our experiments with the acute treatment of cells by dexamethasone for $4 \mathrm{~h}$ showed that MAO-A enzymatic activity was significantly decreased in both cell lines, which is consistent with previous results obtained from living subjects following acute stress. Acute dexamethasone exposure resulted in MAO-A enzyme activity being significantly decreased compared with untreated (control) cells by $33 \%\left(t_{(10)}=3.725, p=0.0039\right)$ in neuroblastoma cells and significantly decreased in glial cells by nearly $29 \%\left(t_{(10)}=3.342\right.$, $p=0.0075)$.

\section{Effects of acute dexamethasone exposure upon MAO-A protein levels in human neuronal and glial cells}

Because MAO-A enzyme activity was significantly decreased in both cell lines, we hypothesized that MAO-A protein expression would also decrease upon acute dexamethasone exposure. To further investigate changes in MAO-A expression induced by short-term stress, the protein expression of MAO-A was analyzed in human SH-SY5Y and 1242-MG cells after undergoing acute stress which is depicted by treating these human cell lines with $100 \mathrm{~nm}$ dexamethasone for $4 \mathrm{~h}$. Upon harvest, total protein lysates of cells were examined by Western blotting. Each MAO-A protein band was evaluated from six independent preparations by measuring its relative intensity and normalizing that value to the density of $\beta$-actin for both SH-SY5Y cells and 1242-MG cells. Student's $t$ test was used to analyze differences between the two groups in each cell line. As we expected, protein levels of MAO-A were decreased compared with untreated (control) cells by $38 \%$ $\left(t_{(10)}=3.195, p=0.0096\right)$ in neuronal cells and significantly decreased in glial cells by $35 \%\left(t_{(10)}=2.860, p=0.0170\right)$ respectively. No change was observed in the housekeeper protein, $\beta$-actin, which was used in the normalization of band intensities.

\section{Discussion}

This is the first study exploring the effects of acute stress on brain MAO-A binding in vivo, in animals of any species. It is also the first to investigate the effects of acute stress upon MAO-A binding in the human brain, and to investigate the effects of acute glucocorticoid exposure upon MAO-A activity and protein levels in human neuroblastoma and glioblastoma cell lines. These convergent findings have ramifications for understanding the role of MAO-A in adaptivity of acute stress in contrast to chronic stress. These findings also suggest specific neural and cellular mechanisms accompanying acute stressors. In addition, the concordant results of the present study support combining radioligand neuroimaging and cell line techniques as multimodal measures for highly dynamic states (Table 2).

We show that decreased MAO-A binding in human brain and decreased MAO-A activity/levels in cell lines follow an acute psychosocial stressor and acute dexamethasone administration, re- 
Table 2. Consistency of main results across methods: stress- or dexamethasone-induced changes in MAO-A binding, levels, and activity

\begin{tabular}{|c|c|c|c|c|c|}
\hline Acute stressor & Investigation & $\begin{array}{l}\text { Region or } \\
\text { cell type }\end{array}$ & $p$ value & $\begin{array}{l}\text { Mean } \% \text { change } \\
\text { [stress minus control] }\end{array}$ & $\begin{array}{l}\text { Direction } \\
\text { of change }\end{array}$ \\
\hline \multirow[t]{11}{*}{ Acute psychosocial stress (TSST and MIST) } & \multirow[t]{11}{*}{ MA0-A $V_{T}$ from $\left[{ }^{11} \mathrm{C}\right]$ harmine $P E T$ in humans } & PFC & 0.01 & $9 \%$ & Decrease \\
\hline & & OFC & 0.004 & $11 \%$ & Decrease \\
\hline & & dIPFC & 0.002 & $15 \%$ & Decrease \\
\hline & & $\mathrm{ACC}$ & 0.043 & $8 \%$ & Decrease \\
\hline & & Temporal cortex & 0.005 & $10 \%$ & Decrease \\
\hline & & Occipital cortex & 0.008 & $9 \%$ & Decrease \\
\hline & & Putamen & 0.021 & $8 \%$ & Decrease \\
\hline & & Caudate & 0.009 & $11 \%$ & Decrease \\
\hline & & Hippocampus & 0.015 & $11 \%$ & Decrease \\
\hline & & Thalamus & 0.014 & $11 \%$ & Decrease \\
\hline & & Midbrain & 0.176 & $5 \%$ & Decrease \\
\hline \multirow[t]{4}{*}{$\begin{array}{l}\text { Acute dexamethasone administration } \\
\qquad(100 \mathrm{~nm})\end{array}$} & \multirow[t]{2}{*}{$\begin{array}{l}\text { MAO-A enzyme activity }(\mathrm{nmol} / 20 \mathrm{~min} / \mathrm{mg} \text { ) from } \\
\text { radiometric catalytic activity assay }\end{array}$} & Neuronal cells & 0.004 & $33 \%$ & Decrease \\
\hline & & Glial cells & 0.008 & $29 \%$ & Decrease \\
\hline & \multirow[t]{2}{*}{ MAO-A density (MAO A/actin ratio) from Western blot } & Neuronal cells & 0.01 & $38 \%$ & Decrease \\
\hline & & Glial cells & 0.017 & $35 \%$ & Decrease \\
\hline
\end{tabular}

Comparison of acute stress-induced and acute dexamethasone-induced changes in living brain, neuronal cell, and glial cell lines. Acute stressor-exposures were $4 \mathrm{~h}$ in both investigations: Trier Social Stress Task and the Montréal Imaging Stress Task (Acute psychosocial stress) and $100 \mathrm{~nm}$ dexamethasone (Pharmacological stress). In vivo brain MAO-A changes were assessed with [ $\left.{ }^{11} \mathrm{C}\right]$ harmine PET imaging after acute psychosocial stressors. MA0-A enzyme activity was assessed by $\left[{ }^{14} \mathrm{C}\right]-5-\mathrm{HT}$ metabolism and liquid scintillation spectroscopy, and MAO-A protein level with Western blot analysis, both in neuronal and glial cell lines, after dexamethasone administration. PFC, Prefrontal cortex; OFC, orbitofrontal cortex; dIPFC, dorsolateral prefrontal cortex; ACC, anterior cingulate cortex.

spectively. Subjects showed the expected stress-induced cortisol and subjective stress-report increases in line with past data (Pruessner et al., 2004). Acute stressors led to in vivo decreases of $7-16 \%$ in whole brain MAO-A binding. $\left[{ }^{11} \mathrm{C}\right]$ harmine binding is generally viewed as an index of MAO-A density, since $V_{\mathrm{T}}$ is highly correlated with known MAO-A density and distribution (Saura et al., 1992; Saura et al., 1996), and data suggest that MAO-A affinity is stable across different brain regions (Bottlaender et al., 2010). Since acute glucocorticoid administration led to an abrupt drop in MAO-A activity and protein levels of $30-33 \%$ and 35$39 \%$, respectively, we feel the mostly likely interpretation of the collective data is that acute stress reduces MAO-A density in brain with functionally relevant consequences of reduced MAO-A activity.

These results are significant in understanding acute stressinduced rapid adaptation in healthy living humans, particularly since decreased MAO-A binding in healthy humans is associated with a normal stress response. This effect of acute stress on MAO-A binding was rapid, opposite in direction, and we propose, possibly beneficial. Stress-induced increased brain 5-HT in particular is viewed as adaptive, since it is key to initiating normal HPA-axis activation, and is associated with rapid alertness and adaptive behavioral stress-responses in rodents (e.g., Dinan, 1996; Clow et al., 1997; Beekman et al., 2005; Linthorst and Reul, 2008). MAO-A has a pivotal role in metabolizing serotonin: Extracellular 5-HT may also be influenced by availability of precursor tryptophan, inhibition of its synthetic enzyme tryptophan hydroxylase, inhibition of serotonin reuptake, but the manipulation that most robustly raises extracellular serotonin is administration of antidepressants that inhibit MAO-A (e.g., Bel and Artigas, 1995; Adell et al., 1996). Since MAO-A metabolizes monoamines, stress-induced decreases in MAO-A binding/activity may be helpful in augmenting the monoamine elevations related to normal behavioral stress-responses and HPA-axis activation (see discussion in Clow et al., 1997). This potentially beneficial effect of acute stress is in line with the stress literature that suggests that the acute physiological, endocrine and behavioral stress response is adaptive, and necessary to allow the individual to mount available energy resources to better cope with an immediate threat, and restore the body's homeostasis. Only when stress becomes a chronic condition it is believed that its effects are detrimental for the individual (Juster et al., 2010).

Our data suggest specific cellular mechanisms regarding acute stressors. One is that acute glucocorticoid treatment may influence MAO-A function via transcriptional means, i.e., through transcriptional repression, since a temporal lag of 2-4 h after treatment of cells with dexamethasone (data not shown) is required for these acute effects on MAO-A activity to evolve. We previously reported that $\mathrm{R} 1$, a repressor protein for MAO-A (Chen et al., 2005), was increased in the cell nucleus when cells were treated with dexamethasone $(100 \mathrm{nM})$ for $<12 \mathrm{~h}$ in human neuroblastoma SK-N-BE(2)-C and glioblastoma 1242-MG cell lines (Ou et al., 2006b). Therefore, it is possible the transcriptional repressor $\mathrm{R} 1$ is involved in the transcriptional repression of MAO-A gene expression during the acute glucocorticoids treatment. Another possible mechanism is that acute stress/dexamethasone directly impairs the translational apparatus (protein synthesis). This has been determined in the skeletal muscle of rat after intraperitoneal injection of dexamethasone for $4 \mathrm{~h}$, which diminished protein synthetic rates $80 \%$ compared with untreated control values in skeletal muscle from rat hindlimb (Shah et al., 2000). Similar results have been found in a rat skeletal muscle cell line (L6 cells) in vitro when treating cells with dexamethasone (1 $\mu \mathrm{M})$ for $4 \mathrm{~h}$ (Wang et al., 2006).

This study demonstrates the advantages of combining cell lines and in vivo imaging. The benefit of $\mathrm{PET}$ is an in vivo assessment of brain stress-responses with regional specificity, and the model is ecologically valid as it uses a psychological stress-challenge. An advantage of cell line data is the control over environmental variables surrounding the cell, and the ability to directly measure protein level and activity. Although the results are in the opposite direction to the effects of chronic stress and longer glucocorticoid exposures, we consider these results well supported due to the agreement of these results across the neuroimaging and cell line investigations, and the use of procedures consistent with our former testing of chronic stressor-situations or longer-term glucocorticoid exposure (Meyer et al., 2006, 2009; Ou et al., 2006b). 
Thus, changes in MAO-A found here are unlikely attributable to spurious results from methodological problems, differences in perceived stress, or environmental confounds.

A limitation of PET neuroimaging is that the HRRT PET camera has a spatial resolution of $3.1 \mathrm{~mm}$, thus the changes observed in MAO-A $V_{\mathrm{T}}$ are not specific to cell type. The proportion of MAO-A $V_{\mathrm{T}}$ that is specific binding is extremely high, being $85 \%$ of the total distribution volume, hence the change in MAO-A $V_{\mathrm{T}}$ was interpreted as a change in MAO-A-specific binding. The overall MAO-A $V_{\mathrm{T}}$ change in the imaging study was $10 \%$, thus, it is possible a within-subject change in free-and-nonspecific distribution volume $\left(V_{\mathrm{F}+\mathrm{NS}}\right)$ of $67 \%$ could create a $10 \% V_{\mathrm{T}}$ change, although this is unlikely since $67 \%$ is a very large effect. Previous investigations find that MAO-A $V_{\mathrm{F}+\mathrm{NS}}$ tends to be stable for this radiotracer, and the concordance with the molecular study this makes it very unlikely that our findings are explained by changes in $V_{\mathrm{F}+\mathrm{NS}}$. Limitations in cell line assays include the inability to yield in vivo data specific to particular brain regions; and it was not within the scope of this study to determine whether the acute glucocorticoid-induced decreases in MAO-A protein levels result via transcriptional mechanisms, translational mechanisms, or both.

To our knowledge, this is the first study to image stress-induced brain MAO-A binding-changes in humans, and the first to measure acute glucocorticoid administration in human brain-derived cell lines. We observed a highly consistent relationship between acute stressors/glucocorticoids and decreased MAO-A binding, activity and protein levels, which we interpret as a rapid decrease in MAO-A density/activity accompanying acute stress or glucocorticoid administration in brain and brain-derived cells. A stress-induced decrease in MAO-A density and activity may be viewed as an adaptive process that raises brain monoamine levels and promotes coping behavior. This phenomenon may explain why acute stressors benefit healthy animals even though chronic stress/glucocorticoids are associated with illness. Our data also suggest that acute stressors, through raising glucocorticoids, are likely to affect MAO-A level by influencing transcriptional repression or by directly regulating protein synthesis. Finally, our study's combination of different methodologies helps decipher the cellular and neural stress mechanisms underlying behavioral stress-responses.

\section{References}

Adell A, Biggs TA, Myers RD (1996) Action of harman (1-methyl-betacarboline) on the brain: body temperature and in vivo efflux of 5-HT from hippocampus of the rat. Neuropharmacology 35:1101-1107. CrossRef Medline

Alia-Klein N, Goldstein RZ, Kriplani A, Logan J, Tomasi D, Williams B, Telang F, Shumay E, Biegon A, Craig IW, Henn F, Wang GJ, Volkow ND, Fowler JS (2008) Brain monoamine oxidase A activity predicts trait aggression. J Neurosci 28:5099-5104. CrossRef Medline

Armando I, Lemoine AP, Segura ET, Barontini MB (1993) The stressinduced reduction in monoamine oxidase (MAO) A activity is reversed by benzodiazepines: role of peripheral benzodiazepine receptors. Cell Mol Neurobiol 13:593-600. CrossRef Medline

Ashburner J, Friston K (1997) Multimodal image coregistration and partitioning - a unified framework. Neuroimage 6:209-217. CrossRef Medline

Ashburner J, Friston KJ (1999) Nonlinear spatial normalization using basis functions. Hum Brain Mapp 7:254-266. CrossRef Medline

Beekman M, Flachskamm C, Linthorst ACE (2005) Effects of exposure to a predator on behaviour and serotonergic neurotransmission in different brain regions of C57BL/6N mice. Eur J Neurosci 21:2825-2836. CrossRef Medline

Bel N, Artigas F (1995) In vivo evidence for the reversible action of the monoamine oxidase inhibitor brofaromine on 5-hydroxytryptamine re- lease in rat brain. Naunyn Schmiedebergs Arch Pharmacol 351:475-482. Medline

Bottlaender M, Valette H, Delforge J, Saba W, Guenther I, Curet O, George P, Dollé F, Grégoire MC (2010) In vivo quantification of monoamine oxidase A in baboon brain: a PET study using [11C]befloxatone and the multi-injection approach. J Cereb Blood Flow Metab 30:792-800. CrossRef Medline

Chen K, Ou XM, Chen G, Choi SH, Shih JC (2005) R1, a novel repressor of the human monoamine oxidase A. J Biol Chem 280:11552-11559. CrossRef Medline

Clow A, Patel S, Najafi M, Evans PD, Hucklebridge F (1997) The cortisol response to psychological challenge is preceded by a transient rise in endogenous inhibitor of monoamine oxidase. Life Sci 61:567-575. CrossRef Medline

Dagher A, Tannenbaum B, Hayashi T, Pruessner JC, McBride D (2009) An acute psychosocial stress enhances the neural response to smoking cues. Brain Res 1293:40-48. CrossRef Medline

Dedovic K, Renwick R, Mahani NK, Engert V, Lupien SJ, Pruessner JC (2005) The Montreal Imaging Stress Task: using functional imaging to investigate the effects of perceiving and processing psychosocial stress in the human brain. J Psychiatry Neurosci 30:319-325. Medline

Dinan TG (1996) Serotonin and the regulation of hypothalamic-pituitaryadrenal axis function. Life Sci 58:1683-1694. CrossRef Medline

Dressendörfer RA, Kirschbaum C, Rohde W, Stahl F, Strasburger CJ (1992) Synthesis of a cortisol-biotin conjugate and evaluation as a tracer in an immunoassay for salivary cortisol measurement. J Steroid Biochem Mol Biol 43:683-692. CrossRef Medline

Drevets WC (2000) Functional anatomical abnormalities in limbic and prefrontal cortical structures in major depression. Prog Brain Res 126:413431. CrossRef Medline

Edelstein SB, Breakefield XO (1986) Monoamine oxidases A and B are differentially regulated by glucocorticoids and "aging" in human skin fibroblasts. Cell Mol Neurobiol 6:121-150. CrossRef Medline

Filipenko ML, Beilina AG, Alekseyenko OV, Dolgov VV, Kudryavtseva NN (2002) Repeated experience of social defeats increases serotonin transporter and monoamine oxidase A mRNA levels in raphe nuclei of male mice. Neurosci Lett 321:25-28. CrossRef Medline

First M, Spitzer R, Williams J, Gibbon M (1995) Structured clinical interview for DSM-IV-non-patient edition (SCID-NP, Version 1.0). Washington DC: American Psychiatric.

Fowler JS, Volkow ND, Wang GJ, Pappas N, Logan J, Shea C, Alexoff D, MacGregor RR, Schlyer DJ, Zezulkova I, Wolf AP (1996) Brain monoamine oxidase A inhibition in cigarette smokers. Proc Natl Acad Sci U S A 93:14065-14069. CrossRef Medline

Frokjaer VG, Mortensen EL, Nielsen FA, Haugbol S, Pinborg LH, Adams KH, Svarer C, Hasselbalch SG, Holm S, Paulson OB, Knudsen GM (2008) Frontolimbic serotonin $2 \mathrm{~A}$ receptor binding in healthy subjects is associated with personality risk factors for affective disorder. Biol Psychiatry 63:569-576. CrossRef Medline

Ginovart N, Meyer JH, Boovariwala A, Hussey D, Rabiner EA, Houle S, Wilson AA (2006) Positron emission tomography quantification of [11C]-harmine binding to monoamine oxidase-A in the human brain. J Cereb Blood Flow Metab 26:330-344. CrossRef Medline

Johnson S, Stockmeier CA, Meyer JH, Austin MC, Albert PR, Wang J, May WL, Rajkowska G, Overholser JC, Jurjus G, Dieter L, Johnson C, Sittman DB, Ou XM (2011) The reduction of R1, a novel repressor protein for monoamine oxidase A, in major depressive disorder. Neuropsychopharmacology 36:2139-2148. CrossRef Medline

Juster RP, McEwen BS, Lupien SJ (2010) Allostatic load biomarkers of chronic stress and impact on health and cognition. Neurosci Biobehav Rev 35:2-16. CrossRef Medline

Kessler RC (1997) The effects of stressful life events on depression. Annu Rev Psychol 48:191-214. CrossRef Medline

Kim-Cohen J, Caspi A, Taylor A, Williams B, Newcombe R, Craig IW, Moffitt TE (2006) MAOA, maltreatment, and gene-environment interaction predicting children's mental health: new evidence and a meta-analysis. Mol Psychiatry 11:903-913. CrossRef Medline

Kirschbaum C, Pirke KM, Hellhammer DH (1993) The 'Trier Social Stress Test'-a tool for investigating psychobiological stress responses in a laboratory setting. Neuropsychobiology 28:76-81. CrossRef Medline

Kirschbaum C, Prüssner JC, Stone AA, Federenko I, Gaab J, Lintz D, Schommer N, Hellhammer DH (1995) Persistent high cortisol responses to 
repeated psychological stress in a subpopulation of healthy men. Psychosom Med 57:468-474. Medline

Lemoine AP, Armando I, Brun JC, Segura ET, Barontini M (1990) Footshock affects heart and brain MAO and MAO inhibitory activity and open field behavior in rats. Pharmacol Biochem Behav 36:85-88. CrossRef Medline

Linthorst AC, Reul JM (2008) Stress and the brain: solving the puzzle using microdialysis. Pharmacol Biochem Behav 90:163-173. CrossRef Medline

Logan J, Fowler JS, Volkow ND, Wolf AP, Dewey SL, Schlyer DJ, MacGregor RR, Hitzemann R, Bendriem B, Gatley SJ (1990) Graphical analysis of reversible radioligand binding from time-activity measurements applied to $\left[N-{ }^{11} \mathrm{C}\right.$-methyl $]-(-)$-cocaine PET studies in human subjects. J Cereb Blood Flow Metab 10:740-747. CrossRef Medline

Love TM, Stohler CS, Zubieta JK (2009) Positron emission tomography measures of endogenous opioid neurotransmission and impulsiveness traits in humans. Arch Gen Psychiatry 66:1124-1134. CrossRef Medline

Lu D, Johnson C, Johnson S, Tazik S, Ou XM (2008) The neuroprotective effect of antidepressant drug via inhibition of TIEG2-MAO B mediated cell death. Drug Discov Ther 2:289-295. Medline

Manoli I, Le H, Alesci S, McFann KK, Su YA, Kino T, Chrousos GP, Blackman MR (2005) Monoamine oxidase-A is a major target gene for glucocorticoids in human skeletal muscle cells. FASEB J 19:1359-1361. Medline

Meyer JH, Ginovart N, Boovariwala A, Sagrati S, Hussey D, Garcia A, Young T, Praschak-Rieder N, Wilson AA, Houle S (2006) Elevated monoamine oxidase A levels in the brain: an explanation for the monoamine imbalance of major depression. Arch Gen Psychiatry 63:1209-1216. CrossRef Medline

Meyer JH, Wilson AA, Sagrati S, Miler L, Rusjan P, Bloomfield PM, Clark M, Sacher J, Voineskos AN, Houle S (2009) Brain monoamine oxidase A binding in major depressive disorder: relationship to selective serotonin reuptake inhibitor treatment, recovery, and recurrence. Arch Gen Psychiatry 66:1304-1312. CrossRef Medline

Ou XM, Chen K, Shih JC (2006a) Monoamine oxidase A and repressor R1 are involved in apoptotic signaling pathway. Proc Natl Acad Sci U S A 103:10923-10928. CrossRef Medline

Ou XM, Chen K, Shih JC (2006b) Glucocorticoid and androgen activation of monoamine oxidase A is regulated differently by R1 and Sp1. J Biol Chem 281:21512-21525. CrossRef Medline

Pruessner JC, Hellhammer DH, Kirschbaum C (1999) Low self-esteem, induced failure and the adrenocortical stress response. Pers Individ Diff 27:477-489. CrossRef

Pruessner JC, Kirschbaum C, Meinlschmid G, Hellhammer DH (2003) Two formulas for computation of the area under the curve represent measures of total hormone concentration versus time-dependent change. Psychoneuroendocrinology 28:916-931. CrossRef Medline
Pruessner JC, Champagne F, Meaney MJ, Dagher A (2004) Dopamine release in response to a psychological stress in humans and its relationship to early life maternal care: a positron emission tomography study using $\left[{ }^{11} \mathrm{C}\right]$ raclopride. J Neurosci 24:2825-2831. CrossRef Medline

Rusjan P, Mamo D, Ginovart N, Hussey D, Vitcu I, Yasuno F, Tetsuya S, Houle S, Kapur S (2006) An automated method for the extraction of regional data from PET images. Psychiatry Res 147:79-89. CrossRef Medline

Saura J, Kettler R, Da Prada M, Richards JG (1992) Quantitative enzyme radioautography with ${ }^{3} \mathrm{H}$-Ro $41-1049$ and ${ }^{3} \mathrm{H}-\mathrm{Ro} 19-6327$ in vitro: localization and abundance of MAO-A and MAO-B in rat CNS, peripheral organs, and human brain. J Neurosci 12:1977-1999. Medline

Saura J, Bleuel Z, Ulrich J, Mendelowitsch A, Chen K, Shih JC, Malherbe P, Da Prada M, Richards JG (1996) Molecular neuroanatomy of human monoamine oxidases A and B revealed by quantitative enzyme radioautography and in situ hybridization histochemistry. Neuroscience 70:755774. CrossRef Medline

Saura J, Andrés N, Andrade C, Ojuel J, Eriksson K, Mahy N (1997) Biphasic and region-specific MAO-B response to aging in normal human brain. Neurobiol Aging 18:497-507. CrossRef Medline

Shah OJ, Anthony JC, Kimball SR, Jefferson LS (2000) Glucocorticoids oppose translational control by leucine in skeletal muscle. Am J Physiol Endocrinol Metab 279:E1185-E1190. Medline

Slotkin TA, Seidler FJ, Ritchie JC (1998) Effects of aging and glucocorticoid treatment on monoamine oxidase subtypes in rat cerebral cortex: therapeutic implications. Brain Res Bull 47:345-348. CrossRef Medline

Soliman A, O'Driscoll GA, Pruessner J, Holahan ALV, Boileau I, Gagnon D, Dagher A (2008) Stress-induced dopamine release in humans at risk of psychosis: a [C-11] raclopride PET study. Neuropsychopharmacology 33: 2033-2041. CrossRef Medline

Soliman A, Bagby RM, Wilson AA, Miler L, Clark M, Rusjan P, Sacher J, Houle S, Meyer JH (2011) Relationship of monoamine oxidase A binding to adaptive and maladaptive personality traits. Psychol Med 41:10511060. CrossRef Medline

Spielberger CD (1977) State-trait anxiety inventory for adults. Redwood City, CA: Mind Garden.

Studholme C, Hill D, Hawkes D (1999) An overlap invariant entropy measure of 3D medical image alignment. Pattern Recognit 32:71-86. CrossRef

Wang H, Kubica N, Ellisen LW, Jefferson LS, Kimball SR (2006) Dexamethasone represses signaling through the mammalian target of rapamycin in muscle cells by enhancing expression of REDD1. J Biol Chem 281:39128 39134. CrossRef Medline 